\title{
External Beam Radiotherapy in Metastatic Bone Pain from Solid Tumours in Zaria, Nigeria
}

\author{
DA Dawotola* \\ VI Odigie** \\ LMD Yusufu** \\ A Adamu* \\ PAbur** \\ AO Jimoh*** \\ MR Mahmud*** \\ AT Ajekigbe**** \\ OB Campbell $* * * * *$
}

Radiotherapy and

Oncology Centre*

Breast and Endocrine Unit

Department of Surgery**

Department of

Neurosurgery***

Ahmadu Bello University

Teaching Hospital, Zaria.

Department of

Radiotherapy****

Lagos University

Teaching Hospital Lagos.

Department of

Radiotherapy*****

University College

Hospital, Ibadan.

All Correspondence:

Dr DADawotola

Radiotherapy and

Oncology Centre

Ahmadu Bello

University Teaching

Hospital, Zaria.

\section{E-Mail:}

david_dawotola@yahoo.com

\section{Introduction}

B one metastasis is a manifestation of late stage of cancer. Its consequences such as bone pains impair patient's quality of life ${ }^{1,2}$. Among the contemporary modalities of metastatic bone pain treatment, radiotherapy has been considered as the treatment of choice ${ }^{3-6}$. Varying incidence $(8.0 \%-19.6 \%)$ of bone metastasis has been recently reported from Nigeria ${ }^{7,8}$.

Bone pain from metastatic cancer can be effectively palliated by external beam irradiation and randomized studies and meta-analyses have described the efficacy of external beam radiotherapy in pain palliation, with the overall responses ranging from $66.0 \%-88.0 \%{ }^{9,10}$. However, the impact of this modality in metastatic bone pain has not been fully studied in our centre which is one of the National centres for oncology in Nigeria.

\section{Patients and Methods}

Consecutive histologically-proven cancer patients in whom the lesion is a primary solid tumour, presenting with metastatic bone pain between January 2006 and December 2008 were prospectively studied. 
All patients had radiological evidence of metastasis. Data collected were demographics, primary tumour site, clinical and radiological metastatic sites, number of metastatic bone deposits, radiation dose and systemic therapy received.

Data were entered into a proforma in prospective study. Evaluation of baseline pain, was done using a linear visual analogue scale (VAS) from 0 to 10 . Analgesic consumption rate was assessed at the commencement of Cobalt -60 photon radiation treatment. The doses of radiation received ranged from $600 \mathrm{cGy}$ to $30 \mathrm{~Gy}$ given in therapeutic fractionations.

Analgesic consumption was evaluated using a 0 to 4 scale (Table 1). Patients were re-evaluated for pain level and the degree of analgesic use at 4 weeks and 12 weeks. Results were analysed using SPSS ver. 15.

\section{Results}

Forty-three patients were studied. There were 10 males and 33 females. Male: Female $=1: 3.3$. Mean age was $44.4 \pm 10.6$ years. Age range was 27 years $75 y e a r s$. Seventy-two point one percent $(72.1 \%)$ of the patients were below the age of 50 years.

The most common primary cancer sites were breast, prostate and cervix accounting for $72.1 \%, 9.3 \%$ and $9.3 \%$ respectively (Fig. 1).

Table 1: Analgesic Score Scale.

\begin{tabular}{ll}
\hline \multicolumn{2}{l}{ Analgesic Score Scale } \\
\hline 0 & none \\
1 & Simple analgesics \\
2 & Mild narcortics \\
3 & Strong narcortics \\
4 & Inadequate narcortics \\
\hline
\end{tabular}

\section{SITE OF PRIMARY MALIGNANCY}

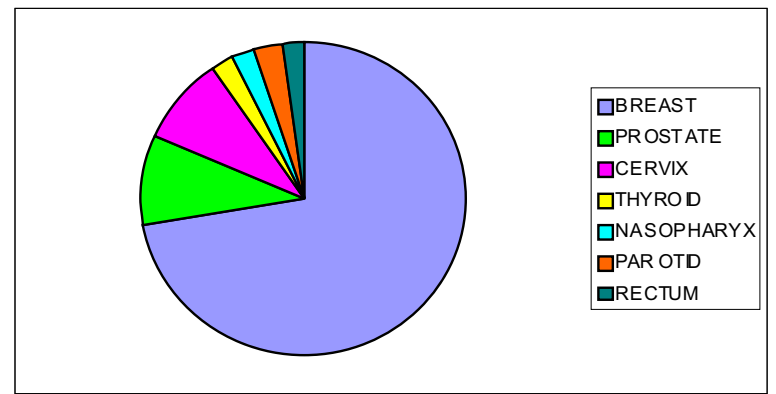

Breast cancer was most common $(\mathbf{7 2 . 1} \%)$ site

Figure 1: Site of Malignancy
Fifty-three point five percent $(53.5 \%)$ of patients had primary disease insitu at presentation. Seventy-four point four percent $(74.4 \%$ ) of patients had movement restrictions while $26.0 \%$ and $4.7 \%$ had sensory loss and autonomic dysfunction respectively at presentation.

The vertebral column was the commonest site of metastatic deposits (Table2).

Table 2: Distribution of Bone Metastases.
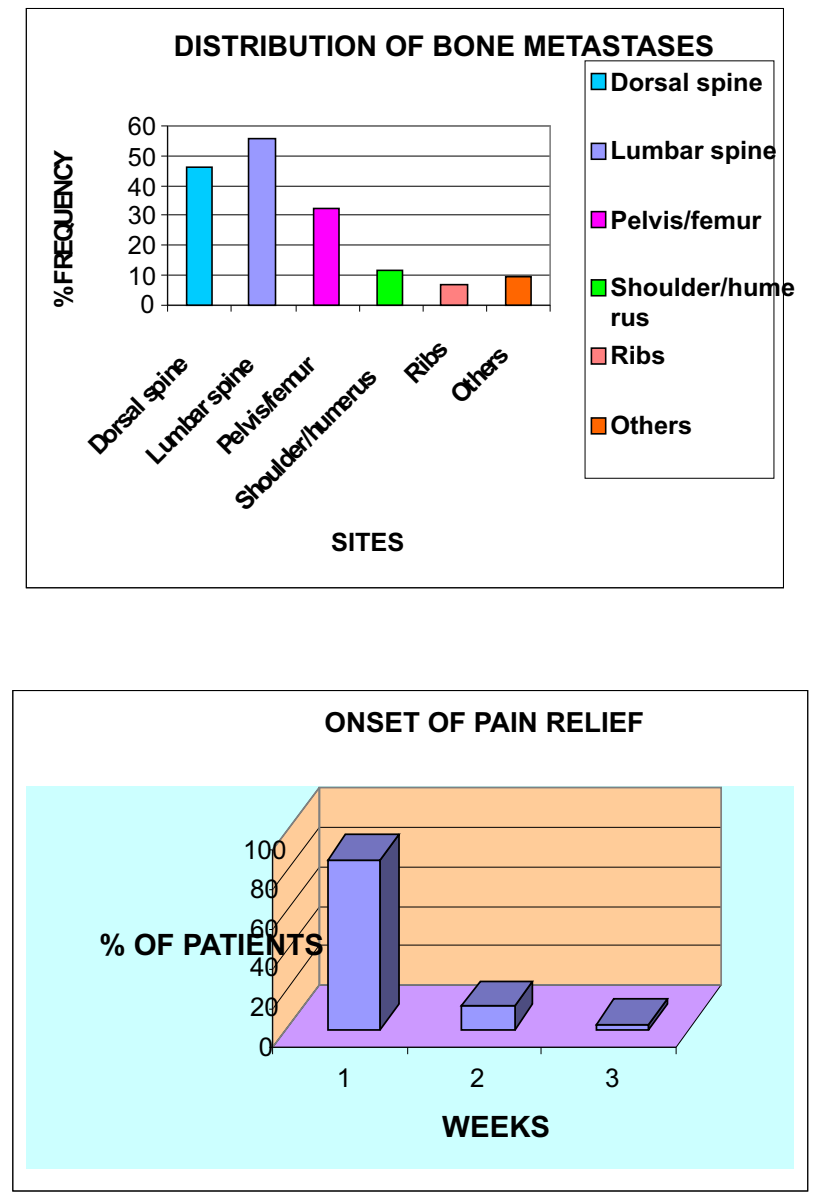

Figure 2: Onset of Pain Relief.

$85 \%$ of the patients had pain relief in the first week of irradiation.

Twenty-three patients (53.4\%) had single site, while the others had two or more bone metastatic sites. Thirty point two percent of patients had visceral metastases.

The mean pain score at baseline was $7.9 \pm 1.5$ while the mean analgesic score was $2.3 \pm 0.5$. (Table 3).Eigthy-six percent of the patients obtained significant pain relief in the first week of treatment using VAS (Fig 2). 
At 12 weeks, the mean pain score and analgesic scores were $0.7 \pm 0.8$ and $0.2 \pm 0.4$ respectively (Table $3)$.

No difference was observed in the onset of pain relief between patients below 40 year and those 40 years and above.

Table 3: Pre and Post Irradiation Scores.

\begin{tabular}{lll}
\hline Weeks & $\begin{array}{l}\text { Mean } \\
\text { Pain } \\
\text { Score (SD) }\end{array}$ & $\begin{array}{l}\text { Mean } \\
\text { Analgesia } \\
\text { Score(SD) }\end{array}$ \\
\hline 0(pre- irradiation) & $7.9(1.5)$ & $2.3(0.5)$ \\
4(post-irradiation) & $2.6(0.9)$ ) & $0.7(0.5)$ \\
12(post-irradiation) & $0.7(0.8)$ & $0.2(0.4)$
\end{tabular}

A significant reduction in both pain and analgesia scores after irradiation : 7.9 vs 0.7 and 2.3 vs 0.2 respectively.

\section{Discussion}

Majority of patients in the study were females and the male to female ratio was $1: 3.3$. This observed preponderance was due to the number of breast cancer patients. It has been variously reported ${ }^{7,11,12}$ that breast cancer is the commonest cancer when both sexes are combined. In Nigeria, it is the most common and sometimes the second most common malignant disease among women ${ }^{13,14}$

The study showed that $72.1 \%$ of the patients were below the age of 50 years, with a mean age of 44.4 years in contrast to reports on Caucasians with bone metastasis with mean age of 66.9 years $\pm 10.7^{15,16}$. Majority of our patients were young $\leq 50$ years old. This is probably a reflection of the observation that cancer afflicts the younger age group in developing countries when compared to industrialized countries $^{17}$. This finding shows that bone metastases occur a decade or two earlier in the African cancer patients and may be due to the demographic profile in developing countries. Breast cancer was the most common primary disease among the study population. This is in accordance with reports in indigenous African populations ${ }^{18}$ and in contrast to reports from the developed countries where other solid tumours, such as prostate and lung cancers, are the most common primary tumours in patients with bone metastases $^{19-22}$.

It is of note that half of the patients had primary disease in situ. This is due to the fact that cancer patients in Nigeria still present to hospitals late, usually with advanced and metastatic diseases ${ }^{7,8}$.
Various reasons for late presentations of cancer patients include fear of the unknown, illiteracy, tradition and cultural beliefs among others ${ }^{23,24}$. Some of the patients had complained of bone pains for not less than 2 months and had visited orthodox medical practitioners and were given non-steroidal antiinflammatory drugs. Seventy-six point seven percent of the patients admitted to using over- thecounter drugs and other native concoctions. The vertebral column was found to be the most common site of bone metastasis.

Similar findings had been reported in the literature ${ }^{25}$. Eighty-six percent of the patients obtained significant pain relief in the first week of treatment and by the 12th week all the patients had achieved significant pain relief. This is in accordance with the reports of other studies ${ }^{26}$. According to literature reports, median time from treatment to pain relief was 3 weeks ${ }^{27}$. The degree of pain relief achieved by the patients could be seen in gradual reduction in the analgesic requirement. During the period of study, none of the patients had pain re-occurrence requiring re-irradiation.

There are various scales for measuring pain in the literature. These include Brief Pain Inventory ${ }^{28}$, Visual Analogue Scale ${ }^{29}$, McGill Pain Questionnaire $(\mathrm{MPQ})^{30}$, Numerical 11 point box (BS-11) $)^{31}, 4$ point verbal rating scale and 101- point scale ${ }^{32}$. The VAS used in this study was found to be simple and easy to understand by the patients. It is the authors opinion that it is useful in low resource country where the patients are not very literate and its use is recommended by the authors.

External beam radiotherapy was well tolerated by the patients in this study. There was no severe side effect observed in any of the patients. Two point three percent of the patients had mild diarrhea and nausea. According to literature report, morbidity associated with palliative radiotherapy for bone metastases is low. The limitation of the study was the number of patients studied and this did not permit further detailed/elaborate statistical analysis. Also the lack of isotope bone scan in our centre limited the detailed evaluation of bone deposits.

It is the authors' opinion that breast cancer is the commonest cause of bone metastasis in the sub region. All patients with bone pains in a cancer setting or had previous surgery for cancer should be intensively evaluated and followed up. External beam irradiation using Cobalt 60 in a low resource setting is still adequate/effective for palliating pain in metastatic cancer patients. 


\section{References}

1. Cocks K, Cohen D, Wisloff F, Sezer O, Lee S, Hippe $\mathrm{E}$, et al. An international field study of the reliability and validity of a disease-specific questionnaire module (the QLQ-MY20) in assessing the quality of life of patients with multiple myeloma. Eur. J. Cancer 43(11), 1670-1678 (2007).

2. Sauer N, Leising D, Wild B, Treiber M, Henningsen $\mathrm{P}$, Jakobsen T. Pain and quality of life following palliative radiotherapy of bone metastases. Strahlenther Onkol. 2006; 182(9):550-556.

3. Nielsen OS, Bentzen SM, Sandberg E, Gadeberg CC, Timothy AR. Randomised trial of single dose versus fractionated palliative radiotherapy of bone metastases. Radiother Oncol 1998; 47; 233-240.

4. Koswig S, Buchali A, Schlenger L, Budach V. Palliative radiotherapy of bone metastases: A retrospective analysis of 176 patients. Strahlenther Onkol 1999; $175:$ 509-514.

5. Hendrickson FR, Shehata WM, Kirchner AB. Radiation therapy for osseous metastasis. Int $\mathrm{J}$ Radiat Oncol Biol Phys 1976;1:275-278.

6. Agarawal JP, Swangsilpa T, Linden Y van der, Rades D, Jeremic B, Hoskin PJ: The Role of External Beam Radiotherapy in the Management of Bone Metastases. Clin Oncol 2006;18(10):747-760.

7. Ketiku KK. The Pattern of metastases in Nigerian Breast Cancer Patients. Clinical Radiology 1986; 37: 563-565.

8. Odigie VI, Yusufu LMD, Rafindadi A, da RochaAfodu J T. Breast Cancer in Zaria Nigeria. Nig J Surg $2003 ; 9(2): 46-50$.

9. Jeremic B. Single fraction external beam radiation therapy in the treatment of localized metastatic bone pain, A review, J Pain symptom management 2001; 22: 1048-1058.

10. Hartsell WF, Scott CB, Bruner DW, Scarantino CW, Ivker RA, Roach M, et al. Randomized trial of short and long-course radiotherapy for palliation of painful bone metastases. J Natl. Cancer Inst 2005; 97: 798-804.

11. Anyanwu SNC. Breast Cancer in Eastern Nigeria. A ten-year review. West Afr J Med. 2000; 19;120-125.

12. Thomas JO. Cancer registration and diagnosis in Ibadan. Archives of Ibadan Medical Research 2000;4: 14-17.

13. Dawotola DA, Olasinde TA. Radiotherapy in cancer management at the Ahmadu Bello University Teaching Hospital, Zaria Nigeria: Assessment of the clinical impact of the new Radiotherapy facilities. Nigerian Medical Practitioner 2004; 45: $45-48$.

14. Afolayan EAO, Rafindadi A. Zaria Cancer Register (1982-1994) Sahel Medicine Journal 2002; 5: 3438.

15. S Kaasaa, E Brenneb, Jo-A Lunda, P Fayersa, U Falkmera, M Holmbergd, et al . Prospective randomised multicenter trial on single fraction radiotherapy (8 Gy!1) versus multiple fractions
(3 Gy!10) in the treatment of painful bone metastases. Radiother Oncol 2006; 79: 278-284.

16. Li KK, Hadi S, Kirou-Mauro A, Chow E. When should we define the response in the treatment of bone metastases by Palliative Radiotherapy? Clin Oncol 2008:20; 83-89.

17. Parkin DM, Muir CS, shelan SI, Gao Y, ferlay J, powell J. Cancer incidence in the five continents. Vol IV Lyon IARC: Scientific publication 1992; 6:120.

18. Parkin D M, Sitas F, Chiranje M, Stein La, Abratt R, Wabinga H. Part 1: cancer in Indigenous Africans burden, distribution, and trends. Lancet oncology 2008: 9;683-692.

19. Mundy G. Mechanisms of bone metastasis. Cancer 1997; 80:1546-1556.

20. Roodman GD.Mechanisms of Bone Metastasis. N Engl J Med 2004;350:1655-1664.

21. Galasko CBS. Incidence and distibuton of skeletal metastases. Clin Orthop 1986; 210: 14-21.

22. Abrams H.L, Spiro R, Goldstein N. Metastases in carcinomas: analysis of 1000 autopsied cases. Cancer 1950; 3: 74-85.

23. Durosinmi-Etti FA. Cancer patients in Nigeria causes of delay in diagnosis and treatment. Nigerian quarterly Journal of Hospital Medicine 1985; 3;2830.

24. Ajekigbe AT. Fear of Mastectomy: The most common factor responsible for late presentation of carcinoma of the breast in Nigeria. Clinical Oncology 1991;3;78-80.

25. Yavuz MN, Yavuz A, Kavgaci H, Ýlis E, Aydin F, Cakirbay $\mathrm{H}$. Effects of pamidronate use on the palliative radiotherapy of bone metastases. Turk $\mathrm{J}$ Cancer 2002;32(2):57-65.

26. Saarto T, Janes R, Tenhuen MM. Palliative radiotherapy in the treatment of skeletal metastases. Eur J Pain $2002 ; 6: 323-330$.

27. Steenland E, Leer JW, van Houwelingen H, Post WJ, van den Hout WB, Kievit J, et al. The effect of a single fraction compared to multiple fractions on painful bone metastases: A global analysis of the Dutch Bone Metastases Study. Radiother Oncol 1999;52:101-109.

28. Cleeland CS, Ryan KM . "Pain assessment: global use of the Brief Pain Inventory". Ann. Acad. Med. Singap. 1994 23 (2): 129138.

29. Huskisson EC . "Measurement of pain". J. Rheumatol. 1982;9(5): 768-769.

30. Melzack R. The McGrill Pain questionnaire: major properties and scoring methods. Pain 1975:1(3): 277-299.

31. Jensen MP, Karoly P, O'Riordan EF, Bland F, Burns RS . "The subjective experience of acute pain. An assessment of the utility of 10 indices". Clin J Pain 1989;5 (2): 153-159.

32.Jensen M P, Karoly P, Braver S. The measurement of clinical pain intensity : A comparison of six methods. Pain 1986; 27: 117-126. 